http://jmscr.igmpublication.org/home/

ISSN (e)-2347-176x ISSN (p) 2455-0450

crossref DOI: https://dx.doi.org/10.18535/jmscr/v7i10.26

Journal Of Medical Science And Clinical Research

IGM Publication

An official Publication of IGM Publication

Original Research Article

\title{
A Descriptive Study of Vitamin D Deficiency in Chronic Urticaria and Its Possible Role in Pathogenesis
}

\section{Authors \\ Premchand TR ${ }^{1}$, Kaviarasan $\mathbf{P K}^{2^{*}}$, Prasad $\mathbf{P V S}^{3}$, Kannambal $\mathbf{K}^{4}$, Poorana $\mathbf{B}^{5}$, Abhirami $\mathbf{C}^{6}$}

${ }^{1}$ Post Graduate, Department of Dermatology Venereology and Leprosy, Rajah Muthiah Medical College \& Hospital, Annamalai University, Chidambaram, India - 608002.

${ }^{2}$ Head of the Department, Department of Dermatology Venereology and Leprosy, Rajah Muthiah Medical College \& Hospital, Annamalai University, Chidambaram, India - 608002.

${ }^{3}$ Professor, Department of Dermatology Venereology and Leprosy, Rajah Muthiah Medical

College \& Hospital, Annamalai University, Chidambaram, India - 608002

${ }^{4}$ Associate professor, Department of Dermatology Venereology and Leprosy, Rajah Muthiah Medical College \&

Hospital, Annamalai University, Chidambaram, India - 608002

${ }^{5}$ Assistant professor, Department of Dermatology Venereology and Leprosy, Rajah Muthiah Medical College \&

Hospital, Annamalai University, Chidambaram, India - 608002

${ }^{6}$ Lecturer, Department of Dermatology Venereology and Leprosy, Rajah Muthiah Medical College \& Hospital,

Annamalai University, Chidambaram, India - 608002

*Corresponding Author

Kaviarasan PK

\begin{abstract}
Background: Chronic urticaria, though is not lethal, it significantly affects the quality of life of patients. The cause is idiopathic in 55\% and autoimmune in $45 \%$ of chronic urticaria cases. Role of vitamin D3 in various immune mediated skin diseases like vitiligo, atopic dermatitis and psoriasis has been already explored and well established. It is now known that chronic urticaria is often triggered by autoimmune reactions, since vitamin $D$ plays an important role in innate and adaptive immunity, it is more likely to be associated with chronic urticaria

Aim: The purpose of the present study was to evaluate the serum vitamin D3 levels and other clinical characteristics in patients of chronic urticaria.

Method: This is a descriptive study which was performed in about 36 subjects with chronic urtcaria who attended the outpatient Department of Dermatology in a tertiary care centre. Serum vitamin D3 levels were measured and stratified into vitamin $D$ deficiency, insufficiency and sufficiency as per standard reference range and compared with healthy controls to ascertain the relationship between vitamin D status and chronic urticaria.

Results: Serum vitamin D3 level was significantly lower in chronic urticaria subjects as compared with the healthy controls. The prevalence of vitamin $D$ deficiency $(<30 \mathrm{ng} / \mathrm{ml})$ was significantly higher in patients with chronic urticaria.

Conclusion: The present study showed a strong positive correlation between vitamin $D$ deficiency and chronic urticaria. This study also warrants that each subject with chronic urticaria should be screened for serum vitamin D3 levels before initiating treatment.

Keywords: Chronic urtricaria, vitamin deficiency, VDR receptors, immunomodulatory, 5D pruritus score, Autologous Serum Skin Test (ASST).
\end{abstract}




\section{Introduction}

Urticaria more commonly known as "hives" is a prevalent disorder that affects between $15-25 \%$ of the population at some point in their lifetime ${ }^{1}$. Chronic urticaria is defined as the presence of evanescent wheals which occur for greater than 6 weeks without an identifiable trigger ${ }^{1}$. The cause remains idiopathic in $55 \%$ and autoimmune in $45 \%$ of cases with circulating histamine releasing antibodies against high affinity $\operatorname{IgE}$ receptor or IgE.

Vitamin D is known to have modulatory effects on dendritic cells and monocytes, and the functional impairment of these cells interferes with the production of various cytokines. The impaired function of various immunocytes due to low vitamin D levels might lead to increase of circulating pro-inflammatory cytokines and imbalance of regulatory T-cell cytokine production, which cause worsening of chronic urticaria $^{2}$.

\section{Method}

This study is a descriptive study which was performed in about 36 study subjects with chronic urtcaria with duration more than 6 weeks who attended the outpatient Department of Dermatology in a tertiary care centre. A detailed written and informed consent was obtained from all the participants and ethical clearance was sought from the institutional ethical committee. Along with the 36 study subjects, an equal number of sex and age-matched healthy volunteers from hospital visitors with no history of urticaria was chosen as the control group. For each patient, a complete medical history, detailed physical and cutaneous examination was done and a questionnaire regarding the characteristics of the disease and exacerbating factors was taken. Routine baseline investigations including complete blood count, urine analysis, ESR, Creactive protein, serum $\mathrm{IgE}$ Helicobacter pylori antibody serology, thyroid function tests were done for all the study subjects. In addition autologous serum skin test (ASST) were performed. Urticarial activity in study subjects were assessed using 5D pruritus score - a multidimensional questionnaire which includes five domains namely degree, duration, direction, disability and distribution of pruritus per 24 hours with minimum score $<8$ to maximum score of $>25$.

Investigations specific to our study like serum 1$25(\mathrm{OH})$ vitamin (vitaminD3) levels were measured in all the study subjects and healthy controls using Chemiluminescent immunoassay technique (CLIA). Values less than $20 \mathrm{ng} / \mathrm{mL}$ were considered as vitamin $\mathrm{D}$ deficient, between $20 \mathrm{ng} / \mathrm{mL}$ and $30 \mathrm{ng} / \mathrm{mL}$ as vitamin D insufficiency, and values more than $30 \mathrm{ng} / \mathrm{mL}$ were categorized as sufficient.

\section{Inclusion Criteria}

Patients aged 14-60 years of either sex, with persistent signs and symptoms of urticaria (itching and wheals) for more than 6 weeks.

\section{Exclusion Criteria}

Children, Pregnant, Lactating mothers, immunocomromised individuals, subjects with acute urticaria were excluded from the study.

\section{Statistical Analysis}

Stastical analysis was performed using IBM SPSS stastics version 20 for windows. The baseline characteristics in the study groups were analysed using ANOVA with 95\% confidence interval for mean and the results were expressed in mean \pm standard deviation. Independent sample't' test was used to compare the mean serum vitamin D3 levels between the study group and healthy control group. Analysis was carried out at 5\% level of significance and $\mathrm{p}<0.05$ was considered as significant.

\section{Results}

A total of 36 study subjects were enrolled in the present study Overall there was no significant difference in age of chronic urticaria subjects (Mean years \pm SD 35.806 \pm 12.7365 ) versus healthy controls (Mean years \pm SD $36.763 \pm 12.7365$ ) and patients were predominantly female (52.8\%) versus males(47.2\%). Mean duration of urticaria 
in months was $15.500 \pm 19.699$. Mean serum $\operatorname{IgE}$ in chronic urticaria subjects was $643.186 \pm 683$ compared to healthy controls $(54.333 \pm 533)$. ASST was found positive in $44.4 \%$ of study subjects. Helicobacter pylori association was found to be
$11.11 \%$ among chronic urticaria subjects. Hypothyroidism association was found to be $13.388 \%$ among the study subjects. Mean 5D pruritus score were higher in vitamin D Deficiency study subjects.

Table1: Clinical characteristics of patients and controls

\begin{tabular}{|l|c|c|c|}
\hline Characteristics & $\begin{array}{c}\text { Chronic urticaria } \\
\text { subjects }(\mathbf{n}=\mathbf{3 6})\end{array}$ & $\begin{array}{c}\text { Healthy controls } \\
(\mathbf{n = 3 6})\end{array}$ & $\begin{array}{c}\text { Significance } \\
\mathbf{P}<\mathbf{0 . 0 5}\end{array}$ \\
\hline Age in months & $35.806 \pm 12.7365$ & $36.763 \pm 12.7365$ & Not significant \\
\hline Gender M :F & $17: 19$ & $18: 18$ & Not significant \\
\hline Mean serum IgE & $643.186 \pm 683$ & $(54.333 \pm 533)$. & Significant \\
\hline Mean5D Pruritus score & $16.700 \pm 1.5347$ & - & - \\
\hline
\end{tabular}

\section{Serum Vitamin D3 Level}

Mean \pm SEM Vit D3 was found to be $21.52 \pm$ $1.428 \mathrm{ng} / \mathrm{ml}$ in chronic urtcaria subjects versus $27.17 \pm 1.677 \mathrm{ng} / \mathrm{ml}$ in healthy controls was proved to be statistically significant by independent paired ' $t$ ' test. (tab.2, fig.1). Low levels of vitamin D levels were observed in $83.4 \%$ of study subjects compared to healthy controls (66.6\%) (tab.3). Females with chronic urticaria had predominantly lower levels of vitamin D (50\%) when compared to males $(33.33 \%)$ (Tab.4 fig.2)

Table 2: Independent paired ' $t$ 'test

\begin{tabular}{|l|c|c|c|c|}
\hline Mean Serum & Study subjects & Healthy Controls & $\mathrm{t}$ value & $\mathrm{p}$ value \\
\cline { 2 - 5 } VitD3 Levels & $21.52 \pm 1.428$ & $27.17 \pm 1.677$ & -2.57 & 0.012 \\
\hline
\end{tabular}

Fig 1

\section{Mean Serum Vit D3 Levels}

27.17

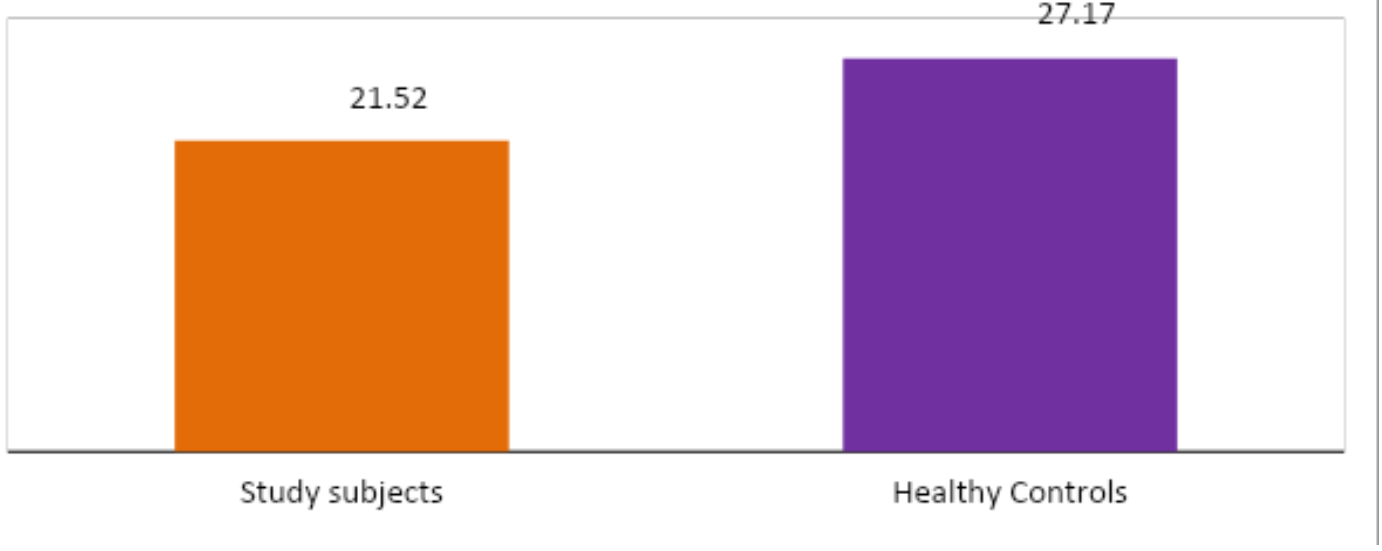

Table 3: Vitamin D status in patients and controls

\begin{tabular}{|l|c|c|}
\hline Vitamin D3 Levels & Study subjects & Healthy controls \\
\hline Vitamin D deficiency & $15(41.66 \%)$ & $8(22.22 \%)$ \\
\hline Vitamin D insufficiency & $15(41.66 \%)$ & $16(44.44 \%)$ \\
\hline Vitamin D Sufficiency & $6(16.66 \%)$ & $12(33.33)$ \\
\hline
\end{tabular}


Table 4: Serum vitamin D3 Levels among gender in study subjects

\begin{tabular}{|l|c|c|}
\hline VITAMIN D LEVELS & MALE & FEMALE \\
\hline Insufficient & $6(16.66 \%)$ & $9(25 \%)$ \\
\hline Deficient & $6(16.66 \%)$ & $9(25 \%)$ \\
\hline Sufficient & $5(13.88 \%)$ & $1(2.77 \%)$ \\
\hline Total & $17(47.22 \%)$ & $19(52.77 \%)$ \\
\hline
\end{tabular}

Fig.2

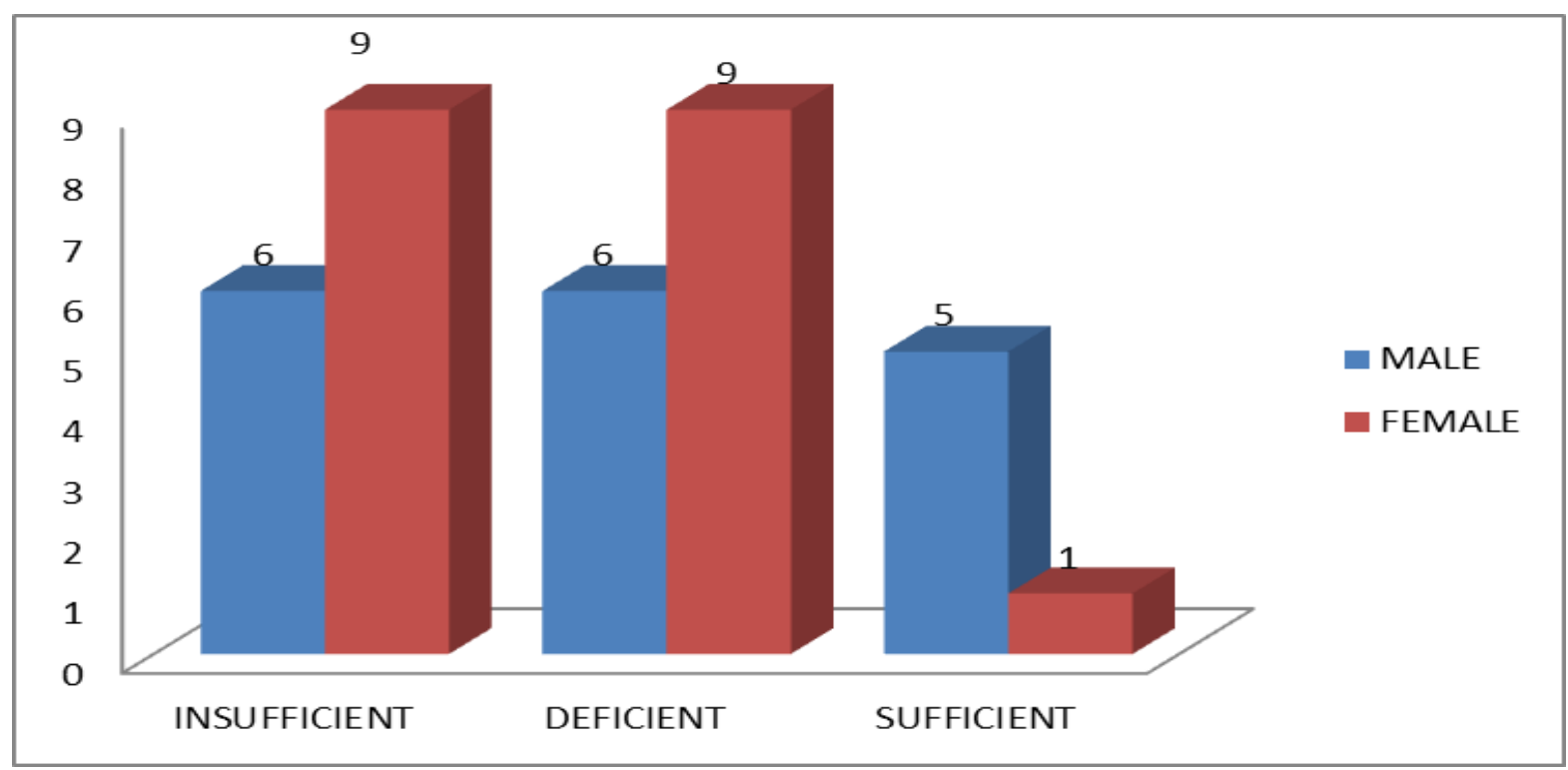

\section{Discussion}

Chronic urticaria, a heterogenous group of skin disease with diverse etiological factors, at times the cause is almost not found, which severely debilitates the day to day activities of the individuals. However in $40 \%$ of cases, chronic urticaria is found to be autoimmune in nature with circulating autoantibodies against IgE and its receptors signifies the role of vitamin $\mathrm{D}$ as a immunomodulator in the pathogenesis of chronic urticaria.

\section{Role of Vitamin D3 In the pathogenesis of chronic urticaria}

Vitamin D can exert immunomodulatory actions in both innate and adaptive immunity primarily by modifying vitamin D receptors (VDR) receptors on mast cells, inhibiting mast cell differentiation and inducing mast cell apoptosis thereby reducing the recurrent episodes of urticaria ${ }^{3}$.

Mast cells express VDR and respond to 1$25(\mathrm{OH})_{2} \mathrm{D} 3$. Mechanism of action for 1$25(\mathrm{OH})_{2} \mathrm{D} 3$ in inhibiting mast cell activity is by means of down-regulating mast cell development, differentiation, and eventually function via VDR, inhibition of IL3, which is a crucial cytokine involved in mast cell survival, proliferation and maturation, induction of apoptosis of bone marrow mast cell precursors, inhibits the release of inflammatory mediators by bone marrow mast cells stimulated by FceRI cross-linking. ${ }^{4}$

Calcitriol also plays a role in mast cell activation and produces interleukin 10 (IL-10) without causing degranulation. Calcitriol maintains mast cell stability and reduces histamine production. Generated IL-10 will inhibit the production of immunoglobulin E-dependent pro-inflammatory mediators. Mediators will reduce leukotriene C4 involved in eosinophil activation process. ${ }^{5}$

Hence, low vitamin D levels might lead to increase of circulating pro-inflammatory cytokines and imbalance of regulatory $\mathrm{T}$-cell cytokine production, which cause worsening of chronic urticaria.

Vitamin D is considered now as a marker for chronic inflammatory disease, but also for the acute phase of inflammation it could be suspected that low vitamin D levels among patients initially presenting with acute urticaria may provide a 
marker for predicting higher probability to progression to the chronic form. ${ }^{2}$

In our study, the mean age in the study group was found to be $35.806 \pm 12.7365$ vs $36.763 \pm 12.7365$. This is similar to previous study done by Chandrasekar et al. ${ }^{6}$ In our study, chronic urticaria patients were predominantly females (52.8\%) versus males $(47.2 \%)$. This female preponderance in chronic urticaria subjects in our study was very similar to previous studies done by chandrasekar et $\mathrm{al}^{6}$ and Andy Rorie et al. Mean duration of chronic urticaria in our study was found to be $36.00 \pm 15.50$ which is similar to previous study done by Nazila Ariaee et al. Mean serum IgE in chronic urticaria subject was found to be $643.186 \pm 683$ compared to healthy controls (54.33 \pm 533$)$. This is similar to study done by Kamini CR et al. ${ }^{7}$ ASST was found to be positive in $44.4 \%$ of the study subjects. This is similar to study done by Bajaj et al. ${ }^{8}$

Our study showed a strong positive correlation between vitamin $\mathrm{D}$ deficiency and chronic urticaria. This is similar to previous studies by Rather et al. who showed a significant reduction in the levels of vitamin D3 in patients with CSU as compared to healthy control, Wu et al. showed that the majority of people with urticaria $(54.6 \%)$ had vitamin D levels below normal limits, Chandrashekar et al. proved Significant lower vitamin D levels among chronic urticaria patients and controls, Rasool et al. (Randomized casecontrol study) showed Low serum 25(OH)D levels in $91 \%$ of CSU patients and $64 \%$ of the healthy subjects. ${ }^{9}$

\section{Limitations of the study}

Our study had a small sample size. Further large scale studies are needed to replicate this association. Since Hypovitaminosis D has been recently established in healthy indian population, low serum vitamin D levels in most of our chronic urticaria subjects is whether due to inadequate diet, less sunlight exposure, pattern of clothing is unclear. Furthermore studies are needed to evaluate the etiopathogenesis of vitamin D and the association in chronic urticaria.

\section{Conclusion}

The present study showed significantly reduced vitamin D3 levels in chronic urticaria subjects compared to healthy controls and explained the possible role of vitamin D3 as a immunomodulator in the pathogenesis of chronic urticaria. This study also warrants that each subject with chronic urticaria should be screened for serum vitamin D3 levels before starting a treatment.

\section{References}

1. Bracken SJ, Abraham S, MacLeod AS. Autoimmune Theories of Chronic Spontaneous Urticaria. Front Immunol. 2019 Mar 29;10:627.

2. Woo YR, Jung KE, Koo DW, Lee JS. Vitamin $D$ as a Marker for Disease Severity in Chronic Urticaria and Its Possible Role in Pathogenesis. Ann Dermatol. 2015 Aug;27(4):423-30.

3. Movahedi et al (2015). Vitamin D Deficiency in Chronic Idiopathic Urticaria. Iranian journal of allergy, asthma, and immunology.

4. Baroni E, Biffi M, Benigni F, et al.: VDRdependent regulation of mast cell maturation mediated by 1 , 25dihydroxyvitamin D3. J Leukoc Biol 2007, 81:250-262.

5. Astri Adelia, Larisa Paramitha Wibawa, Adhimukti T Sampurna, Windy K Budianti, FaridaZubier. The role of oral vitamin D in several skin diseases $\mathrm{J}$ Gen Proceed Dermatol Venereol Indones. 2017;2(1):18-23.

6. Chandrashekar, L., Rajappa, M., Munisamy, M., et al. (2014). 25-Hydroxy vitamin $\mathrm{D}$ levels in chronic urticaria and its correlation with disease severity from a tertiary care centre in South India. Clinical 
Chemistry and Laboratory Medicine (CCLM), 2019;52(6), pp. e115-e118.

7. Kamini CR, Prasad PVS, Kaviarasan PK, Kannambal K A prospective analysis on relationship between serum IgE levels and severity of chronic urticaria Global Journal For Research Analysis,Volume-5, Issue10, October 2016.

8. Bajaj A K, Saraswat A, Upadhyay A, Damisetty R, Dhar S. Autologous serum therapy in chronic urticaria: Old wine in a new bottle. Indian J Dermatol Venereol Leprol 2008;74:109-13.

9. Tuchinda, Papapit et al. "Relationship between vitamin $\mathrm{D}$ and chronic spontaneous urticaria: a systematic review." Clinical and translational allergy (2018). 